\title{
"Existe uma Alagoas Colonial?" Notas Preliminares sobre os conceitos de uma Conquista Ultramarina
}

Antonio Filipe Pereira Caetano* Universidade Federal de Alagoas

\begin{abstract}
Resumo
É sabido que a região que hoje conhecemos como Alagoas pertenceu até os idos de 1817 a Capitania de Pernambuco, fazendo-se, assim, integrante ao Império Ultramarino Português. Apesar da expressão "Alagoas" ser recorrentemente utilizada para designar aquele espaço mesmo antes da sua emancipação, alguns historiadores e estudos rejeitam tanto o uso da terminologia como a própria existência de uma região constituída isolada do mundo Pernambucano. Assim, o presente artigo pretende analisar os limites e os problemas nestas interpretações, visando construir um esboço conceitual para definir, enquadrar e delimitar os territórios posteriormente conhecido como Vila das Alagoas (1817).
\end{abstract}

Palavras-chave: colonização portuguesa; conceitos; Alagoas Colonial.

\section{Abstract}

It is known that the region known today as Alagoas belonged to the back in 1817 the captaincy of Pernambuco, becoming thus integral to the Portuguese Overseas Empire. Although the term "Alagoas"; is repeatedly used to describe that space even before emancipation, some historians reject both studies and the use of terminology such as the existence of a region made up from the world Pernambucano. Thus, this article analyzes the limits and problems in these interpretations, in order to build a conceptual sketch to define, govern and define the territory later known as the Village of Alagoas (1817).

Key words: Portuguese colonization; concept; colonial Alagoas.

Em um certo momento, Élcio Gusmão Verçosa, trazia a luz uma pergunta, no mínimo, provocativa: existe uma cultura alagoana? Tal questionamento, o educador tentava responder em uma obra homônima de caráter ensaístico, simplório e com traços de inovação ${ }^{1}$. Tentando se afastar de uma história ufanista - o que descaradamente não consegue fazer no final - enxerga a formação cultural desta localidade como algo plural e atemporal, levantando a pista de que uma sociedade se constrói a partir de manifestações próprias, principalmente no que se refere aos elementos culturais. Sem dúvida, uma das maiores argumentações de seu trabalho, mas não chega a ser uma novidade pensando no debate teórico "atual"".

Retrocedendo à história balizada pelos Institutos Históricos e Geográficos espalhados pelo Brasil ao longo do século XIX, destacava que a formação da cultura alagoana passava pelo entendimento da fusão dos elementos potiguaras (caetés, em uma linguagem local), da introdução dos descendentes

\footnotetext{
* Doutor em História pela Universidade Federal de Pernambuco e professor adjunto do Curso de História da Universidade Federal de Alagoas.

1 VERÇOSA, Élcio Gusmão. Existe uma Cultura Alagoana? Maceió: Catavento, 2002.

2 Para isso ver CERTEAU, Michael de. A Invenção do Cotidiano. Petrópolis: Vozes, 2 Volumes, 1994; ou BHABHA, Homi. O Local da Cultura. Belo Horizonte: EDUFMG, 2007.
} 
de Zumbi dos Palmares e a das imposições dos proprietários como Cristóvão Linz. No entanto, para o autor, dois momentos consagrariam a construção da identidade cultural regional: o movimento de 1817, que culminou na independência alagoana frente à Capitania de Pernambuco, mas que ao mesmo tempo demonstrou a inexistência de grupos letrados para a condução da política regional; e a efetivação da subsidiária da escola positivista em terras alagoanas, o IHGAL, destacado como o responsável por delinear a civilidade e salvaguardar o pilar documental do Estado. Ah, deve-se se ressaltar também um salutar destaque dado aos partidos políticos que ganhariam escopo profissionalizante, auxiliando na construção do "ser alagoano".

Mais crítico, erudito e aprofundado, Dirceu Lindoso entra nesse debate qualificando a cultura alagoana com aspectos "anfíbios", marcada por sedimentações e rupturas ${ }^{3}$. Com um conceito de cultura muito próximo ao de Verçosa, este autor se afasta completamente ao pensar o IHGAL como preservador cultural e não como reprodutor, bem como apresenta a idéia de intelectual "medíocre" formador da imagem do passado alagoano cuja intenção era reforçar o êxito histórico das classes senhoriais em detrimento daqueles que se opunham ao regime estamental. Estes últimos seriam dignos de serem estudados, como os Cabanos.

Outro ponto que aproxima Verçosa e Lindoso diz respeito à escolha da data de 1817 como divisora de águas na formação do que é ser alagoano. Se para o primeiro, o episódio descortinaria as falhas locais, para o segundo entende-se como o resultado das especificidades do território. Assim, para Lindoso, as peculiaridades da cultura alagoana já estariam explícitas na documentação do período, então recorremos a uma delas para identificar tais elementos. Em 20 de janeiro de 1818, o ouvidor geral das Alagoas, Antonio Batalha escrevia carta ao governador geral da Bahia [D. Marcos de Noronha e Brito, o Conde de Arcos] sobre o quadro no qual se encontrava a localidade após a "revolução" de Pernambuco.

Em meio a este corpus, encontra-se cópia de uma proclamação registrada pelo escrivão da comarca, Antonio David de Souza Coutinho, feita

\footnotetext{
${ }^{3}$ LINDOSO, Dirceu. A Interpretação da Província: Estudo da Cultura Alagoana. Maceió: Edufal, 2005.
} 
pelo Tenente Coronel Antonio José Vitorino Borges, em 15 de dezembro de 1817, após sua fuga da região. Dizia o militar:

[...] a minha ausência de entre vos meus honrados Patriotas não foi desamor, nem tão pouco a intenção de desampara vos, antes pelo contrario; o sincero desejo que tinha de proteger hum Povo tão benemérito como fiel ao grito da razão, e aos interesses da Pátria, cuja causa é também a nossa, mas que se achava desprovida de meios e de forças para propugnar pela sua defesa e segurança, quando desígnios perversos, e malvados, tramavam conjurações atrozes, e procuravam desunir os Cidadãos formando cizânias e partidos opostos a nossa liberdade tão bem começada quão fundada na justiça, e nas Leis da Razão da natureza e das gentes ${ }^{4}$.

A afirmação valorizava o "povo alagoano" resgatando o papel heróico dos habitantes na perspectiva de manutenção da união da coroa portuguesa em terras americanas. Interessante é perceber já o uso do termo "pátria", talvez ainda relacionado ao ideal luso-brasileiro, característico do momento de virada do oitocentos para o novecentos. Com uma identidade ainda híbrida, destacase a contraposição daqueles que lutavam para um rompimento das amarras lusitanas [os pernambucanos] e aqueles que visavam à paz. O que o levava a conclusão:

[...] o que agora vos levo para de uma vez estabelecer a ordem, e o sossego publico nesse feliz país; onde direis esperar me qualquer dias tranqüilos, e certos de que acabarmos de uma vez com esses malvados, que pretendem perturbar a nossa paz, e união, e roubar a nossa felicidade que o céu protege, e há de prosperar ${ }^{5}$.

Enfim, olhar este documento e pensar no contexto produtor daqueles episódios nos faz concluir que a maior especificidade daqueles que viviam no território que hoje conhecemos como Alagoas fora justamente não se entender como integrantes e contemplados com as reivindicações dos amotinados da Capitania de Pernambuco contra a Coroa Portuguesa, ainda em território americano. O que, automaticamente, implica em dizer que os "alagoanos" acreditavam que ao se manterem aliados ao monarca poderiam the render benefícios mais interessantes e vantajosos. É maquiavélico pensar dessa forma? Claro que é! Mas ao mesmo tempo não podemos deixar de pensar que a lógica da cultura política do Antigo Regime era permeada de negociação,

\footnotetext{
${ }^{4}$ Arquivo Histórico Ultramarino, Alagoas Avulsos, Documento 471, grifo nosso.

${ }^{5}$ Idem, Ibidem.
} 
barganhas e pactos essenciais para a construção da governabilidade ${ }^{6}$. Recurso usado em tempos remotos pelos vitoriosos pernambucanos no pos bellum holandês, como bem destacou Evaldo Cabral de Mello ${ }^{7}$.

Mas, enfim, o fato é que a emancipação da região alagoana conquistada naquele episódio nos traz recorrentemente a dúvida sobre a formação da identidade local delineada naquele momento. Lindoso diz que sim, Verçosa tem mais certeza ainda sobre isso. Porém, se avaliarmos que 1817 é um negócio muito bem tramado por uma elite local, pode nos levar a sugerir a hipótese de que ali se tem o start dessa identidade, mas seus contornos seriam desenhados a posteri, mesmo que usando de elementos ab initio. Ou seja, os elementos alagoanos estariam cravados exatamente quando este lugar não era Alagoas. Ou era? Afinal, o que era o território que hoje conhecemos como Alagoas entre 1500 e 1817? Podemos chamar de Alagoas? Ou isso era Pernambuco, já que a independência só se dá em 1817? Ops, encruzilhada! Momento bom para o historiador!

Lindoso e Verçosa são equânimes quando apontam o período colonial como a ocasião em que é moldado o ser alagoano. Então o ser precede o território ou o território precede o ser? Se não existisse Alagoas como existiria o ser alagoano em 1817? Voltemos, então, a questão inicial: existe uma Alagoas colonial? Ops, dúvida para o historiador! O grande problema a resolver! Dificuldade esta que se propõe as linhas que se seguem a partir deste momento. Desta feita, o que se pretende aqui é exatamente esboçar uma resposta para essa pergunta capciosa, que nada é mais do que dar um nome a um lugar. Para isso, é importante ser dito que o caminho que vai ser traçado tem como base o uso da documentação que entrelaça às três localidades em tela: o reino português, a capitania pernambucana e a localidade que hoje conhecemos como Alagoas.

São correspondências, cartas, requerimentos, enfim, uma gama de vestígios que revelam o cotidiano local e, mais do que isso, descortinam como o local se denominava e era designado pelos outros. O uso da documentação do Arquivo Histórico Ultramarino não sei se é o melhor caminho para responder

6 GREENE, Jack P. Negotied Authorithies - Essays in Colonial Political and Constitucional History. Charlottesville/Londres: The University Press of Virginia, 1994.

7 Ver MELLO, Evaldo Cabral. Rubro Veio - 0 Imaginário da Restauração Pernambucana. Rio de Janeiro: Toopbooks, 2002. 
a esta pergunta, mas, sem dúvida, o se debruçar sobre estes corpus documental é o que se tem para o dia, para o momento... um vestígio do passado, que como nos ensina, Gizburgo, podem revelar sinais de um paradigma indiciário ${ }^{8}$. No entanto, antes de recorrer a ela, é necessário fazer um delineamento teórico e conceitual, aparar as arestas e demonstrar o que nos entendemos por América Portuguesa e, consequentemente, Alagoas Colonial.

\section{Um conceito, uma palavra, um lugar...}

Reza o bom funcionamento da lingüística que toda palavra/signo é formada por um significante e um significado. O primeiro nos remete a idéia de como este signo é escrito ou falado, enquanto o segundo nos transporta para a concretização do objeto, ou seja, a representação do conteúdo, de uma idéia. De uma forma simplória, podemos dizer que quando escrevemos ou falamos açúcar identificamos a forma usada pela língua portuguesa para corporificar linguisticamente esta palavra, sendo este seu significante; porém, quando olhamos ou escutamos esta palavra e a associamos aqueles grãozinhos brancos, refinados em um usina e usados para adocicar a vida e as coisas, temos seu significado, que permanece intacto mesmo que alterássemos o seu significante para sugar, em inglês.

Isto implica dizer que toda palavra expressa uma idéia, um significado, um sentido; mas podemos falar, então, que todo signo nos anunciaria um conceito? Para Reihnhart Koselleck, a resposta é negativa! Tentando construir uma história dos conceitos, este historiador alemão nos instiga primeiramente a separar palavra e conceito, apontados como elementos distintos ${ }^{9}$. O que atribui uma palavra a se constituir como conceito seria exatamente esta possuir sentidos que interessam, resultado de um entendimento reflexivo e de uma teorização historicamente construída. Uma palavra, por si só, expressaria somente um sentido, um conteúdo.

Outro elemento que define um conceito remete-se aos critérios de sua seleção. Dessa forma,

\footnotetext{
${ }^{8}$ Cf. GINZBURG, Carlo. Mitos, Emblemas \& Sinais. São Paulo: Companhia das Letras, 1989.

9 KOSELLECK, Reinhart. "Uma História de Conceitos: Problemas Teóricos e Práticos" In: Estudos Históricos. Rio de Janeiro, Volume 5, Número 10, 1992, p. 134-146.
} 
Todo conceito articula-se a um certo contexto sobre o qual também pode atuar, tornando-o compreensível. Pode-se entender esta formulação tornando-o mais instigante. [...] O que significa dizer que todo conceito está imbricado em um emaranhado de perguntas e respostas, textos/contextos ${ }^{10}$.

Assim, a relação entre texto e contextos também seria essencial para demarcar a peculiaridade de um determinado conceito. Como o conceito reflete um contexto específico em uma determinada época, logicamente ele é singular, exclusivo para aquele determinado fato. No entanto, para Koselleck, mesmo que o significante permaneça inalterado, circunstâncias podem alterar o significado daquele conceito conforme a época que estamos nos remetendo. Para o nosso caso, por exemplo, usar o conceito de nobreza para identificar aqueles detentores de poder no Antigo Regime, deve ser balizado para os dois lados do Atlântico, já que a nobreza do reino, costumeiramente, estava associada ao grupo que hereditariamente possui ascendência nobre, que atravessa gerações e, por conta desta característica, tinham direitos à aquisição de benefícios; cruzando o mar, a nobreza das conquistas, apesar da permanência de seu significante, explicitaria o grupo ligado à obtenção de terra, proprietários de uma farta escravaria, ocupantes de cargos administrativos e melhorados de condição se fossem oriundos dos "primeiros conquistadores do território"11. Ou seja, com uma mesma palavra podemos forjar novos conceitos, atribuindo outros sentidos históricos e interpretações contextuais aos signos. Como mesmo o autor remonta: a palavra é a mesma, mas ganhou outro valor.

Apropriando-se desta discussão e tentando buscar um denominador comum, pensando "Alagoas" como uma palavra nos remeteria a um Estado, localizado no Nordeste, marcado por sua economia açucareira e por suas belíssimas praias. Fazendo este mesmo esforço no que tange ao enquadramento como conceito, ela sozinha, não expressaria resultado algum. "Alagoas" como conceito não nos remete a nenhum "fato indicador", nem mesmo único, reflexo de uma situação. É pueril! Apenas nos conectando ao

\footnotetext{
10 Idem, pp. 166-137.

${ }^{11}$ Sobre esta questão ver: BICALHO, Maria Fernanda Baptista. "As Câmaras Ultramarinas e o Governo do Império" In: FRAGOSO, João; GOUVEIA, Maria de Fátima \& BICALHO, Maria Fernanda Baptista (Orgs.) O Antigo Regime nos Trópicos - A Dinâmica Imperial Portuguesa (Séculos XVI-XVIII). Rio de Janeiro: Civilização Brasileira, 2001, pp. 189-222.
} 
território cortado por inúmeras lagoas, demarcando uma característica que seria usada para denominar e/ou nomear a localidade: "a terra entre as lagoas".

Diferentemente acontece quando recorremos ao signo "colônia" de maneira isolada, o que nos possibilita o enquadramento da expressão como um conceito. Colônia ou colonização nos transporta para um fato específico que percorre a história da humanidade. Apesar estarmos preocupados com 0 signo na conjuntura moderna, o mesmo significante pode ser verificado no mundo antigo e na época contemporânea. Evidentemente que a acepção modifica conforme o contexto histórico, o que implica em dizer que a colonização dos romanos sobre os gregos, pouco ou nada possui de semelhante ao imposto pelos lusitanos para fazer valer suas intenções mercantilistas.

No caso brasílico, a conceito de colônia ganhou fôlego não só na historiografia tradicional do século XIX demarcada por Francisco Adolfo Varnhagem, como também pelos autores do início do século XX que tentaram imprimir seus olhares sobre a realidade daquele momento culpando o mundo colonial como o grande responsável pelas mazelas do país contemporâneo ${ }^{12}$. Neste caso, o antagonismo colônia versus metrópole fazia jus à sobreposição do último sobre o primeiro, e da extrema dependência política e econômica dos "brasileiros" em relação aos lusitanos. Assim, se forjava um Estado centralizado e um "sentido da colonização" voltado única e exclusivamente para o atendimento dos anseios econômicos de Portugal, ou seja, o escoamento da produção açucareira.

Logo, o conceito de colônia usado desta maneira implicaria, automaticamente, na inexistência de uma vivência própria daqueles que estavam no outro lado do Atlântico, e mais do que isso demonstrava que os interesses locais eram deixados de fora em detrimento de um anseio maior e centralizador. Usando de uma historiografia renovadora, sobretudo construída por "brasilianista", uma nova visão tem sido descortinada nessa relação entre

\footnotetext{
12 Só para citar três exemplos: JUNIOR, Caio Prado. Formação do Brasil Contemporâneo. São Paulo: Publifolha, 2000; HOLANDA, Sérgio Buarque de. Raízes do Brasil. São Paulo: Companhia das Letras, 2002; NOVAIS, Fernando. Portugal e Brasil na Crise do Antigo Sistema Colonial. São Paulo: Hucitec, 1995.
} 
Portugal e suas terras no Atlântico ${ }^{13}$. Opta-se, neste caso, pela substituição do conceito de colônia pela expressão conquista ou domínio, desvendando por traz uma intenção de suprimir as relações unilaterais e demarcando a idéia de um império vasto, hiper-conectado, diferenciado e ajustado conforme a lógica de cada uma das localidades.

No entanto, a idéia de império em detrimento a de colônia apesar de tentar resolver a equação mal resolvida nos dois lados do Atlântico, também pode pender para uma supervalorização dos elementos ultramarinos de maneira totalmente autônoma e sem relação alguma com o reino. Por conta disso, em nosso entendimento pensar o conceito de colônia e seus derivados demanda uma critica constante, não só fugindo da relação enrijecida do colonizador versus colonizados/colonos - totalmente démodé - mas também reconhecendo os interesses mercantilistas e exploradores da políticaeconômica metropolitana que demandam a imposição de padrões de comportamentos, de anseios financeiros e atitudes políticas. No entanto, não se pode perder de vista que nessa relação de "estica e puxa" a negociação é o elemento moderador tanto para a garantia da autoridade política como dos interesses daqueles que cruzam o Atlântico para construir uma nova vida nos Trópicos.

E o que falar então de "Alagoas Colonial"? Em primeiro lugar devemos pensar que esta se configura nada mais do que uma expressão. Se formos utilizar a referência teórica exposta por Koselleck, a mesma não pode ser entendida como um conceito, pelas questões já referendadas acima; ao pensarmos como uma palavra, não tem sentido, por sua própria natureza lingüística. Por conta disso, o uso desta expressão remete-se unicamente a fusão de dois signos que remetem a um significado e um significante. Ou seja, por mais que soubéssemos que esta não era utilizada no período vigente, o termo "Alagoas Colonial" pode ser pensado como uma expressão que traduz 0 período alagoano entre 1500 a 1822 . Neste caso até dispensamos o 1817 ! Evidentemente que isso é um risco, mas preferimos ponderar seu uso como uma convenção, da mesma maneira que indiscriminadamente se usa o termo

${ }^{13}$ Cf. BOXER, Charles R. 0 Império Marítimo Português. São Paulo: Companhia das Letras, 2002; RUSSELLWOOD, A. J. R. 0 Mundo em Movimento: os Portugueses na Ásia, África e América. Lisboa: Difel, 1998; HESPANHA, Antonio Manuel. As Vesperas do Leviatã - Instituições e Poder Político, Portugal Século XVIII. Coimba: Livaria Almedina, 1994. 
Brasil para qualificar o território existente neste mesmo corte cronológico, quando na verdade durante um bom tempo Brasil era sinônimo apenas de Pernambuco, Rio de Janeiro e Bahia.

No entanto, por mais que apontemos Alagoas Colonial com uma expressão no sentido macro, uma análise das expressões locais também deve ser levada em consideração. Assim, o que estamos querendo dizer é mesmo que usássemos este termo para determinar um território em uma dada época, seria fulcral ver nos papéis como eles se denominavam e como Portugal e Pernambuco nomeavam estas conquistas. É exatamente ai que começa a confusão, e vamos à ela..

\title{
Várias Conquistas imiscuídas a Capitania de Pernambuco...
}

Quando D. João III [o piedoso], em 10 de março de 1534, instaura a política de distribuição de capitanias hereditárias visando um melhor controle do território para afastar a presença de monarquias inimigas do território americano, este concedeu a Duarte Coelho os seguintes chãos:

\begin{abstract}
Sessenta léguas de terra [...] as quais começarão no rio São Francisco [...] e acabarão no rio que cerca em redondo toda a llha de Itamaracá, ao qual ora novamente ponho nome rio [de] Santa Cruz [...] e ficará com o dito Duarte Coelho a terra da banda Sul, e o dito rio onde Cristóvão Jacques fez a primeira casa de minha feitoria e a cinqüenta passos da dita casa da feitoria pelo rio adentro ao longo da praia se porá um padrão de minhas armas, e do dito padrão se lançará uma linha ao Oeste pela terra firme adentro e a terra da dita linha para o Sul será do dito Duarte Coelho, e do dito padrão pelo rio abaixo para a barra e mar, ficará assim mesmo com ele Duarte Coelho a metade do dito rio de Santa Cruz para a banda do Sul e assim entrará na dita terra e demarcação dela todo o dito Rio de São Francisco e a metade do Rio de Santa Cruz pela demarcação sobredita, pelos quais rios ele dará serventia aos vizinhos dele, de uma parte e da outra [... $]^{14}$
\end{abstract}

Assim, a configuração do território da Capitania de Pernambuco era demarcada de um lado pelo rio Santa Cruz e do outro pelo Rio São Francisco, denotando a idéia de que a ocupação teria como referência às margens dos rios caudalosos. No entanto, se para a maioria das cartas de sesmarias régias concedidas para este momento o fracasso fez parte da experiência, no caso das terras doadas a Duarte Coelho não se pode falar a mesma coisa. $O$ sucesso da ocupação fez valer as determinações endereçadas a um capitão donatário que incluíam a composição de uma estrutura administrativa (ouvidor,

\footnotetext{
${ }^{14}$ http://pt.wikipedia.org/wiki/Capitania_de_Pernambuco, data 02/04/2010, 11:55.
} 
tabeliães), desenvolver o sistema jurídico (punição de crimes), aplicar a defesa do território, organizar as eleições, desenvolver a economia (navegação, impostos e monopólios) e, o mais importante, dar estatuto de vila a qualquer povoação da capitania, tendo cada uma por termo três léguas sertão adentro ${ }^{15}$.

Por isso, a grande particularidade destes primeiros tempos de conquista refere-se à configuração da capitania de Pernambuco de cunho privado, o que, de uma certa maneira, possibilitava uma relativa autonomia ao capitãodonatário guardando dentro de sua administração elementos de cunho público e privado. Diferente do que aconteceu em outras regiões brasílicas quando se instituiu a falência da experiência das capitanias hereditárias, levando a coroa portuguesa a uma redistribuição de sesmarias e um controle administrativo sobre estas novas regiões. O caráter privado fica latente ao perceber a listagem dos governadores pernambucanos até a invasão holandesa em 1630, se denotando a presença da família Duarte e Albuquerque instituindo um padrão de colonização e ocupação do território ${ }^{16}$.

Verticalizando a discussão, nesta primeira etapa (1534-1630), a região "alagoana" seria identificada em seu principio pela menção ao Rio de São Francisco, marco de um dos espaços ocupacionais do território. Todavia, a delimitação do ambiente vai ser resultado da política de controle das conquistas, da ampliação dos tentáculos físicos e do desenvolvimento da economia açucareira implementada por Duarte Coelho. Porém, não se exclui, antes disso, as experiências exploratórias sobre a região como ocorridas em Barra Grande (Maragogi), as expedições de Gonçalo Coelho (1512) e a contenção dos franceses por Gaspar de Lemos.

Assim, o primeiro passo para o desenho dos chãos "alagoanos" deu-se com a fundação de Penedo, em 1570. Dirceu Lindoso considerou esse território como uma savana sertaneja às margens do rio São Francisco ${ }^{17}$. Devido a uma grande presença indígena se desenvolveria ali uma colonização sertaneja, com poucas plantações, elevada criação bovina e uma forte presença religiosa. Logo, o espaço de Penedo demarcou a introdução do

\footnotetext{
15 SALGADO, Graça (Coord.). Fiscais e Meirinhos - A Administração no Brasil Colonial. Rio de Janeiro: Nova Fronteira, 1985, p. 128.

${ }^{16}$ A título de informação segue a lista: 1534-1561, Duarte Coelho; 1561-1577, Duarte Coelho de Albuquerque; 15781602; Jorge de Albuquerque Coelho; 1603-1630, Duarte de Albuquerque Coelho. Todos eles entremeados por regentes e lugar-tenente.

17 LINDOSO, Dirceu. Formação da Alagoas Boreal. Maceió: Catavento, 2000, p. 38.
} 
sertão e o aumento da exploração do extremo sul da Capitania de Pernambuco, ou seja, os limites mais intensos que percorreriam o rio São Francisco. Sua elevação a condição de vila somente se deu em 1636, sob o controle flamengo, dotando-a de mais liberdade na gestão administrativa.

Fruto de uma estratégia de defesa militar pernambucana, Cristóvão Linz receberia carta de sesmaria, em 1575, numa zona permeada por quatro rios [Manguaba, Camarajibe, Santo Antonio Grande e Tatuamunha] dando origem a ocupação de Porto Calvo. A concessão da terra tinha por intenção a criação de uma espécie de cordão de isolamento dos índios selvagens que permeavam a banda sul da capitania, conhecimento adquirido após o massacre dos Caetés na região de Coruripe, em 1556. Desta feita, o território da Nossa Senhora de Apresentação de Porto Calvo se desenhou com contornos muito semelhantes aqueles encontrados em Olinda, sede da capitania, a saber: grande concentração de escravos, produção e comercialização da economia açucareira e desenvolvimento de um grupo senhorial que disputava o poder local. Interessante é perceber que Porto Calvo eleva-se também a condição de vila no mesmo ano de Penedo.

Por fim, a composição territorial é encerrada com a formação do pólo lagunar entre Mundaú e Manguaba. Segundo Josemary Ferrrare existe uma controversa sobre a real ocupação daquelas localidades de acordo com a duplicidade de distribuição de sesmarias, já que Diogo Soares da Cunha e Diogo de Melo e Castro teriam recebido as mesmas faixas de terras em $1591^{18}$. No entanto, o primeiro que teria de fato ocupado o território em 1614 construiu um povoamento com sede em Santa Maria Madalena da Alagoa do Sul. Por sua posição centralizada, as lagoas do norte e do sul canalizavam a produção das outras duas localidades acima citadas, contribuindo, também para estabelecer as relações entre elas. Além disso, também havia se transformado em vila no ano de 1636.

Diante deste quadro, podemos dizer que entre 1534 e 1630, a expressão Alagoas remete-se exclusivamente a esta última vila central e lagunar, porém um território vasto que se estendia desde a atual Santa Luzia do Norte até Marechal Deodoro, ou se formos mais ousados, São Miguel dos Campos. A

${ }^{18}$ FERRARE, Josemary. Marechal Deodoro: Um itinerário de Referências Culturais. Maceió: Catavento, 2002, p. 15. 
expressão para abrigar todo o território não era percebido. Muito pelo contrário! Mesmo com uma parca documentação para este momento, percebe-se o uso das três localidades Penedo, Porto Calvo e Santa Luzia como termos para definir localidades que faziam parte de uma mesma faixa de terra, a saber, Capitania de Pernambuco. Logo, isto implica em dizer que as regiões eram vistas como independentes e autônomas entre si, devendo obediência ao governador e/ou capitão-donatário da região pernambucana.

O período subseqüente a este, 1630-1654, que coincide com o momento da ocupação batava da capitania de Pernambuco o quadro de nomeação do território permanece inalterado. No entanto, há de se ressaltar que, com base em Moreno Brandão, as três vilas foram ocupadas em momentos distintos, demonstrando a compreensão de autonomia entre elas; mas, por outro lado, grande parte daqueles territórios se tornavam um refúgio propício para os pernambucanos assolados pelos holandeses ${ }^{19}$.

O fim do período holandês trouxe a necessidade de uma redefinição territorial e a abertura de novos espaços para negociação. Porém, a inexistência de um centro administrativo e o poder dos proprietários de terras que permaneceram em momento de luta contra os batavos deixariam marcas sublinhares da composição política-econômica local. Por outro lado, a preocupação em ocupar efetivamente Maceió e desenvolver sua proteção fora colocado como ponto de pauta no governo de Fernando de Souza Coutinho [1670-1674]. Outro problema latente do território remetia-se a grande presença de formação quilombola, transformando-se em questão prioritária na gestão da capitania. O crescimento da economia açucareira e a conseqüente entrada exacerbada de africanos contribui para desencadeamento de resistências nas Matas regionais. Por conta disso, talvez se explique a falta de percepção ou expressão do território no momento pos bellum.

Contudo, foi justamente nesta conjuntura que a documentação do Conselho Ultramarino nos descortina uma visão, no mínimo curiosa, para aquelas localidades. No primeiro documento da coleção especificamente sobre Alagoas referente a uma Informação prestada sobre os serviços de um capitão, em 1680, assim percebemos:

${ }^{19}$ BRANDÃO, Moreno. História de Alagoas. Arapiraca: Edual, 2004, pp. 42-57. 
O capitão Miguel da Cunha Leite conta que tem servido a Vossa Alteza na Capitania das Alagoas de Juiz dos Órfãos, Escrivão da Câmara, Juiz Ordinário, Capitão de Infantaria da Ordenança desde o ano de 1670 até o de 1674 em que veio para o reino com licença, havendo-se acabado em o ano de 1688 na entrada que fez ao Palmar [... $]^{20}$.

O relato é interessante porque demonstra um súdito português que atuava na manutenção e crescimento da conquista, e ao contrário de muitos documentos dessa natureza, não solicita absolutamente nada ao monarca, apenas informando suas atividades. Também pudera, Miguel Leite possui nada mais, nada menos do que quatro cargos que envolviam arrecadação de riquezas, defesa e atuação administrativa. O que nos interessa, neste caso, é a forma que o próprio Conselho Ultramarino usa para se referir ao local onde 0 capitão atuava: Capitania das Alagoas. Situação até nova e inédita em documentos. Sabemos, evidentemente, que seria uma exceção, uma demonstração isolada, porém não deixa de ser singular detectar que o olhar administrativo já via aquelas territórios distintos como fazendo parte de uma única região: a Alagoas. Mesmo que os próprios habitantes ainda não enxergassem dessa forma, já que os documentos subseqüentes a estes revelam o uso das expressões "vila de Porto Calvo" "Vila de São Francisco" ou "Vila das Alagoas", esta última se referindo a Santa Maria Madalena. Mais sui generis ainda se torna quando pensamos que a criação da comarca somente se daria na centúria seguinte. Vejamos o impacto desta alteração.

\section{Uma Comarca, uma delimitação, uma identificação...}

Em 26 de Maio de 1712, os membros da câmara da Vila de Santa Maria Magdalena Alagoa do Sul escrevia carta a D. Pedro II agradecendo o bom cuidar de seus vassalos. Nas linhas, apontavam:

\footnotetext{
Não há muitos anos que esta Câmara da Vila das Alagoas representou a Vossa Majestade o quanto convinha ao Serviço Real, e a conservação dos seus moradores, que houvessem nela um Ministro de vara branca que ocupasse o cargo de Ouvidor Geral com jurisdição na Vila de Porto Calvo, e no Rio de São Francisco, e sem demora na resolução, foi Vossa Majestade logo servido responder a esta câmara que mandaria um Ministro de toda a suposição que administrasse justiça $[\ldots]^{21}$
}

\footnotetext{
${ }^{20}$ Arquivo Histórico Ultramarino, Alagoas Avulsos, Documento 1, fl. 1. 0 texto foi transcrito conforme a escrita atual e os grifos são nossos.

${ }^{21}$ Arquivo Histórico Ultramarino, Alagoas Avulsos, Documento 10, fl. 1, grifo nosso.
} 
E complementavam:

[...] foi Vossa Majestade servido, pela sua real grandeza (sem mais atenção do que olhar pelo bem e aumento de seus vassalos) eleger ao Dr. Joseph da Cunha Soares para que viesse exercer nesta Vila o cargo de Ouvidor Geral e Corregedor da Comarca com jurisdição na Vila do Porto Calvo, e do Rio de São Francisco [... $]^{22}$

Esses trechos corporificam um dos momentos mais importantes para o entendimento do "mundo colonial alagoano": a criação da comarca. Explicitamente nele percebemos os súditos da região central entendendo-se como fazendo parte de uma nova realidade, reflexo de anseios antigos daquelas conquistas. Segundo os moradores da "Vila das Alagoas" a opção por esta localidade abrigar a sede seria a mais sensata, já que Porto Calvo encontrava-se muito distante da Vila do Rio São Francisco, considerada uma das mais perigosas e tumultuosas entre elas. Além disso, em Santa Maria Magdalena já havia uma estrutura de cargos que ajudava na composição da comarca [almotaçaria e escrivão dos órfãos]. No entanto, há de ser ressaltado, que este não foi um consenso entre aquelas vilas, pois três anos antes, os moradores da Vila de Porto Calvo e Rio São Francisco também tinham escrito ao Conselho solicitando a criação dos cargos de Ouvidor-geral exclusivamente naquelas localidades ${ }^{23}$. Acreditamos que tal fato demonstra o quanto estas conquistas ainda se viam de forma isolada e com pouca conexão entre elas a não ser o vínculo com a Capitania de Pernambuco.

De qualquer forma, a criação da comarca das Alagoas, oficialmente se procedeu em 6 de outubro de 1706 transformando "Vila da Alagoa do Sul" como sua cabeça e Vila de Porto Calvo e Vila de São Francisco [Penedo] como termos da comarca. Segundo Isabel Loureiro, apesar da criação da comarca ter ocorrido nesta data, os entreveros na Capitania de Pernambuco entre senhores de engenho e comerciantes [evento que ficou conhecido como Guerra dos Mascates, 1710-1711] acabou adiando a concretização efetiva do funcionamento do novo órgão administrativo ${ }^{24}$. Situação que pode ser

\footnotetext{
22 Idem, Ibidem.

${ }^{23}$ Arquivo Histórico Ultramarino, Alagoas Avulsos, Documento 8.

${ }^{24}$ ALBUQUERQUE, Isabel Loureiro de. História de Alagoas. Maceió: Sergassa, 2000, p. 70.
} 
constatada facilmente na documentação, pois a referência a mesma só começou a acontecer a partir de 1712, com as fontes acima citadas.

Assim, a instituição de uma Comarca remete a uma delimitação judiciária nos espaços ultramarinos, já que o Ouvidor tem as funções tanto do cotidiano jurídico, passando pelo controle dos ânimos/tumultos até a administração do político $^{25}$. Na prática ele funcionaria como uma espécie de governador de capitania quando as localidades não possuíam este ofício, para aquelas que já a tinha o mesmo ficaria restrito ao mundo legal. No que tange a comarca das Alagoas, o que se percebe é que ao mesmo tempo em que a nova administração institui um personagem [muitas vezes persona non gratta aos súditos locais] com poderes importantes sobre moradores, também institui um novo olhar sobre o território, uma nova nomenclatura, ou seja, uma nova forma de denominar a parte sul da Capitania de Pernambuco.

Voltemos então à documentação para compreender um pouco essa tessitura de designações...

$\mathrm{Na}$ carta acima apontada, percebe-se o uso das vilas ainda como autônomas cada uma se remetendo a sua realidade, normalmente atrelada a expressão "Capitania de Pernambuco" no ato da redação das linhas. No entanto, um elemento já se percebe a partir do inicio do Setecentos, a adoção do termo "Vila das Alagoas" em substituição a Santa Maria Magadalena Alagoa do Sul. Essa mudança seria fulcral para designação posterior do que viria a ser este território, momento em que essa expressão passaria de fato a abranger todas as vilas daquelas bandas. $E$ mais do que isso, sendo naturalmente usada tanto pelo corpus administrativo como por aqueles que viviam naquela localidade.

No entanto, entre 1706 [ou se preferimos, 1712] até 1817 há uma intensa oscilação na maneira de denominar a região, dependendo daqueles que escrevem o documento, informando ou fazendo solicitações. Por exemplo, Simião de Araújo, queria uma provisão para o ofício de escrivão, escreveu a coroa portuguesa, em 21 de Agosto de 1732, em busca do atendimento de seus anseios, e assim se identifica:

${ }^{25}$ SALGADO, Op. Cit. 
Diz Simião de Araújo morador na vila de Penedo, Comarca da vila de Alagoas, que a serventia do oficio de Escrivão da Ouvidoria da mesma Comarca se acha vaga e nele suplicante concorrem todos os requisitos necessários para bem poder servir o dito oficio ${ }^{26}$.

A mesma situação acontece com Miguel de Amorim, que solicitava o pagamento pelo serviço prestado em uma Igreja em 26 de Outubro de 1736:

Diz Miguel de Amorim morador no termo da Vila do Porto Calvo que pela suplica que a Câmara e vigário da dita Vila fez a Vossa Majestade foi servido fazer mercê a Matriz dela de um conto de réis para se fazer a Capela mor $[\ldots]^{27}$

Ou, para encerrar esse grupo, um requerimento de José Pereira de Castro, escrito já na virada do século, em 18 de janeiro de 1800:

Diz José Pereira de Castro, que ele foi nomeado pelo Governador do Estado de Pernambuco, nomeado Mestre de Campo do Terço auxiliar da Villa das Alagoas como foi ver da Patente inclusa, e por que precisa que Vossa Alteza Real Ihe confirme ${ }^{28}$.

Nos três casos percebe-se o uso da expressão vila identificando o lugar de origem, o que implica em dizer que estes indivíduos se identificavam pertencentes aquelas localidades, ou seja, antes de pertenceram a uma Comarca, se inseriam no espaço a partir da acepção mais local ou de procedência. A relação vila/comarca fica evidente no texto de Simião de Araújo, que insere uma na outra, primeiro se remete da onde vem [vila de Penedo] e depois aponta a onde está essa vila [Comarca das Alagoas]. Esta seria uma forma recorrente daqueles que viviam nas conquistas "alagoanas" se expressarem junto aos órgãos administrativos. O grande perigo desta situação é a percepção de quando o termo "Vila das Alagoas" se refere à região somente entre os rios Munduá/Manguabá e quando a mesma expressão remete-se a quase toda região que hoje compreendemos como Alagoas.

Situação percebida, em uma certidão feita pelo escrivão Manuel de Santiago Nogueira, em 23 de Setembro de 1744:

Manoel de Santiago Nogueira escrivão da Câmara nesta vila de Santa Maria Magdalena da Lagoa do Sul e seu Termo distrito da Capitania de Pernambuco por Sua Majestade que Deus Guarde Etc. Certifico

\footnotetext{
${ }^{26}$ Arquivo Histórico Ultramarino, Alagoas Avulsos, Documento 76, fl. 1, grifo nosso.

${ }^{27}$ Arquivo Histórico Ultramarino. Alagoas Avulsos, Documento 93, fl. 1, grifo nosso.

${ }^{28}$ Arquivo Histórico Ultramarino, Alagoas Avulsos, Documento 282, fl. 1, grifo nosso.
} 
que a folhas cento e trinta do livro que serve de Registro das ordens neste Senado fica Registrada há nova ordem de Sua Majestade de vinte de Março deste presente ano que trata sobre as sesmarias e posse o Referido na verdade do dito Livro a que me Reporto é que passei a presente por duas vias por mim assinadas a ordem do Ilustríssimo e Excelentíssimo Senhor Governador e Capitão General de Pernambuco nesta Villa das Alagoas aos vinte e três de Setembro de 1744 anos $^{29}$.

Aqui podemos detectar o uso das três expressões de uma mesma localidade "vila de Santa Maria Magdalena da Lagoa do Sul", "Vila das Alagoas" e "Capitania de Pernambuco". A primeira para informação do lugar de atuação do oficial, a segunda fazendo menção a quem pertencia àquela vila e a terceira já sinalizando a compreensão de um espaço que abrigaria todas as localidades [Alagoas, Porto Calvo e Penedo]. Neste caso, podemos sugerir uma hipótese de que a partir de 1712, o uso da expressão "Vila das Alagoas" começava a se referir ao território inteiro [comarca e seus termos], quando esse significado não procedia, ela viria associada diretamente com o uso dos termos das outras vilas e para se remeter a Vila das Alagoas ou se retornava a expressão de Santa Maria Magdalena como também se inseria a palavra "sul" para diferenciar da terminologia de toda a comarca.

Tal costume fica translúcido quando olhamos a documentação dos próprios gestores coloniais naquelas conquistas. Em consulta do Conselho Ultramarino, de 4 de abril de 1724, assim se remete ao espaço:

Vendo-se neste conselho a carta inclusa de 4 de Novembro do ano passado em que o ouvidor geral da Villa das Alagoas Manoel de Almeida Matoso dá conta a Vossa Majestade da causa que o obrigou a prender a Seu antecessor João Vilela do Amaral[.... $]^{30}$

Ou ainda pensando em um caso mais específico, o requerimento do próprio ouvidor Antonio Rabelo Leite, em 21 de fevereiro de 1733:

Diz o Doutor Antonio Rabelo Leite, Ouvidor da Vila das Alagoas, por seu procurador, que Vossa Majestade foi servido despachar para Ouvidor da dita Vila ao Bacharel João Rodriguez da Silva Ayala e para efeito de Se tirar Residência ao Suplicante Necessita que Se lhe passe ordem $[\ldots]^{31}$

\footnotetext{
${ }^{29}$ Arquivo Histórico Ultramarino, Alagoas Avulsos, Documento 113, fl. 1, grifo nosso.

${ }^{30}$ Arquivo Histórico Ultramarino, Alagoas Avulsos, Documento 27, fl. 1, grifo nosso.

${ }^{31}$ Arquivo Histórico Ultramarino, Alagoas Avulsos, Documento 81, fl. 1, grifo nosso.
} 
Enfim, nos dois documentos, oriundos da estrutura administrativa oficial, o uso da expressão "Vila das Alagoas" já possuía o significado de todo o território que compreendia as três vilas, demarcando a inserção jurídica e política que o espaço adquiriu a partir de 1706. Isso também pode ser percebido, em caso de documentos de outras regiões do "território alagoano", que ainda não tinham ganho o estatuto de vila, ainda permanecendo como freguesia ou paróquia. Caso exemplar encontra-se no documento de um militar, em 6 de julho de 1740, quando assim se expressa: Diz o capitão mor reformado João Marinho Falcão morador na freguesia de São Miguel da Vila das Alagoas que ele serviu a Vossa Majestade com toda a satisfação no posto de Capitão mor da dita Freguesia $[. . .]^{32}$. Logo, neste caso, o uso do termo Vila das Alagoas remeter-se-ia exclusivamente a composição espacial que abrigava tanto as três vilas como outras freguesias que faziam parte daquela região. Sem dúvida, há uma complexificação do uso desta expressão que acabou transformando um termo que nomeava uma administração jurídico-político para uma expressão que dava contornos, delineamentos e, nome, a um determinado lugar.

Por sua natureza de dependência administrativa à capitania de Pernambuco, o termo "Vila das Alagoas" acabou por se consolidar e se popularizar na documentação como o recurso interessante de expressão de identidade, pelo menos geográfica, já que em relação aos súditos ainda não temos bagagem e dados suficientes para afirmar tal suposição. Entretanto, levando em consideração que a organização espacial da América portuguesa era formada por Capitanias, compostas por vilas e, por conseguinte, estas distribuídas em freguesias e paróquias, a convenção "Vila das Alagoas", neste caso, expressa uma unidade territorial, mas não uma independência, nem muito menos a identidade de um povo, talvez, quem sabe, um incentivo para o mesmo!

Para complicar ainda mais toda esta historia de denominações, vamos dar uma olhada no documento 21 e que se desmembra no documento 22 da coleção do Arquivo Histórico Ultramarino sobre Alagoas. O mesmo se refere a uma consulta feita pelo próprio Conselho Ultramarino ao rei sobre a substituição do ouvidor João Vilela do Amaral por Manuel de Almeida Matoso,

\footnotetext{
32 Arquivo Histórico Ultramarino, Alagoas Avulsos, Documento 103, fl. 1, grifo nosso.
} 
circunstância permeada de acusações, intrigas e disputa pelo poder. Formada por diversas cartas entre gestores, o documento descortina a complicada relação entre capitania/vila. Quando o governador de Pernambuco [Manoel de Souza Tavares] escreveu ao ouvidor das Alagoas, em 6 de abril de 1720, assim se expressou:

Senhor Doutor Ouvidor geral da Villa das Alagoas que esta vossa mercê fazendo nessa Capitania das Alagoas do Porto Calvo, e Rio de Sam Francisco, nomeações e provimentos de ofícios, não devendo vossa mercê por nenhum título intrometer se em semelhante procedimento porquanto El Rei meu Senhor, só ao Governador de Pernambuco concede jurisdição para prover geralmente todos os ofícios de justiça e fazendo destas capitanias e não a nenhum Ministro que venha servir nelas ${ }^{33}$.

Em outra carta, do próprio João Vilela do Amaral, neste conjunto, no mesmo dia, aponta:

O Senhor Governador de Pernambuco Manoel de Souza Tavares, nos deu conta em carta do mês de julho deste ano da qual vossa mercê esta provendo todos os ofícios de justiça das Vilas dessa Capitania das Alagoas, não the tocando, escrevendo outros danos, vendo o resoluto que cobra os novos direitos que é estilo pagar nessa dos ditos provimentos a fazenda Real e que querendo evitar este procedimentos[...] $]^{34}$

E, por fim, os membros da câmara de Porto Calvo, suplicavam:

[...] todos juntos clamam, e pedem humildemente aos pés de Vossa Majestade que como Rei Católico, e Príncipe piedoso Ihes comuniquem o remédio de que necessitam suas aflições e que nesta vila se tire a residência deste Ministro donde os molestados deporão suas queixas por quanto os moradores e capitania das Alagoas, cabeça da comarca que dista desta vinte e cinco léguas não tem cabal notícia de que se queixam os moradores deste lugar[...] $]^{35}$

Nas três circunstâncias, o termo Capitania das Alagoas foi usado para nomear o espaço alagoano de uma forma ampla! No primeiro caso, a impressão que se dá é que o governador de Pernambuco transformava as três localidades em uma capitania só; no segundo pedido o ouvidor associa vila e capitania como termos distintos, separados, como se a Vila das Alagoas estivesse presente na Capitania das Alagoas, ou seja, a primeira referia-se a Santa Maria Magdalena; e por fim, a câmara de Porto Calvo denomina a Vila das Alagoas como Capitania das Alagoas, já que associa a expressão cabeça

\footnotetext{
${ }^{33}$ Arquivo Histórico Ultramarino, Alagoas Avulsos, Documento 21, fl. 48, grifo nosso

34 Idem, fl. 49, grifo nosso.

35 Idem, Ibidem, fl. 24, grifo nosso.
} 
da comarca. Sem dúvida é um cenário rico e instigante para interpretação, dentre as várias possibilidades de análise, sugerimos, quem sabe, a consolidação para os grupos ligados ao poder (pelo menos), bem como aqueles entrelaçados na malha administrativa régia no ultramar, a plena consciência de estar se tratando de uma região com características próprias, contornos específicos e um cotidiano político, econômico e social, nem tão diferente, mas um pouco distinto da Capitania de Pernambuco.

Ainda nesses casos não percebemos o uso da expressão capitania atrelada ao estatuto de independência, porém nos leva a uma tentadora concepção destes contornos físicos se desenhando. Assim, afirmamos mais uma vez que mesmo que a autonomia não seja o resultado da criação da comarca, a instituição deste órgão muito mais do que instituir um regime jurídico-administrativo na região também fora a grande responsável por mapear fisicamente suas três vilas, constituindo-a de um desenho bem diferente da Capitania de Pernambuco, por mais que ainda permanecesse atrelada a ela.

A independência conquistada em 1817, concordando com Lindoso, foi uma resposta imediata a uma consolidação física territorial ilustrada em 1706/1712, como também fruto de uma elite local que buscava um aparelho estatal livre da intervenção pernambucana, ampliando as possibilidades de aquisição de cargos e benefícios. Mas, não foi só isso! Acreditamos que 1817, também sinalizou uma posição, uma tomada de lado e adoção de um projeto. Este que pregava o afastamento de Pernambuco [que visava à emancipação frente ao reino] e a aproximação e manutenção da fidelidade ao monarca lusitano "tropicalizado" no Rio de Janeiro. Em resposta, a comarca das Alagoas passava a ganhar o estatuto de Província, autônoma e submissa diretamente a corte carioca/metrópole interiorizada ${ }^{36}$. Desta forma, todos os 61 documentos da coleção referente a Alagoas do período posterior a insurreição pernambucana lançam as expressões Província das Alagoas, Junta Provincial das Alagoas ou Ouvidor Geral das Alagoas.

Interessante assinalar que por mais que a partir deste momento o uso da expressão Alagoas (atrelada ou não a Província) possa ser usada de maneira confortável, não acreditamos que anteriormente a isso também não poderia ser

${ }^{36}$ Aqui apropriando-se da expressão forjada por DIAS, Maria Odila Silva. "A Interiorização da Metrópole" In: Carlos Guilherme Motta (Org.) 1822: Dimensões. São Paulo: Perspectiva, 1972, pp. 160-186. 
feito. O cuidado que se deveria tomar era o da associação do termo Alagoas ao de independência, ai sim extremamente anacrônico! Por mais que usemos Vila das Alagoas entre 1706/1712-1817 temos sempre que sinalizar a submissão desta região à Capitania de Pernambuco. Pois, acreditamos que ainda nesse período seus moradores, e consequentemente, os súditos da coroa portuguesa ainda se viam como pertencentes à Vila de Porto Calvo, Vila de Penedo [ou São Francisco] ou Vila de Santa Maria Magdalena Alagoa do Sul. O problema de toda essa história é a identificação dos súditos como pertencentes a esta região, ou seja, a diminuição do uso dos termos de vila para a utilização de Província. O que implicaria dizer que seus habitantes antes de se denominarem "Porto Calvenses" se entenderiam como "alagoanos".

Não sabemos se isso se funda no ato de 1817, muito pouco provável, até pelo jogo político e clientelístico que envolve tal feito. De qualquer forma, essa seria a grande função do aparelho estatal forjado neste momento: a construção de uma identidade alagoana, ou mais do que isso, a consolidação do desenho político-administrativo e geográfico feito em 1706 para o reconhecimento daqueles que habitavam naquelas bandas de suas características culturais e sociais semelhantes. Não queremos aqui defender, assim, a fundação da cultura de um povo, até porque cultura não se funda, ela é inerente ao ser humano, a uma sociedade e a um tempo. Acreditamos na fundação e/ou invenção de um Estado, o Estado Alagoano! Estado este que buscaria características similares desse povo, elementos já existentes, frutos do processo colonial e da formação territorial para a definição do que seria a identidade alagoana.

Enfim, o que se tentou fazer nestas linhas foi um esforço de buscar um nome para um lugar em um determinado período histórico. Nesta procura sugerimos o afastamento do uso desse nome como um conceito, seguindo a linha interpretativa de Reinhart Kosselleck. Desta forma, se apropriando do termo expressão para nomear aquelas bandas imiscuídas na sesmaria de Duarte Coelho em 1534. Por isso, defendemos a legalidade do termo "Alagoas Colonial" como uma expressão genérica que abarcaria um período entre 15001822 de uma região conquistada pela coroa portuguesa e submetida até 1817 
ao domínio administrativo pernambucano, quando consegue sua autonomia. Esta convenção - sempre entre aspas, por favor - funda-se no próprio risco atribuído ao uso da expressão Brasil Colonial, talvez também um equívoco se for tomada "ao pé da letra"!

No entanto, é preciso delimitar as características dessa expressão, percebendo até que ponto ela nos remete a idéia de uma identidade alagoana. Por conta disso, acreditamos que entre 1500-1630, a localidade era denominada por suas regiões de sesmaria e conquista [Porto Calvo, Penedo, Alagoa do Sul], ainda extremamente dispersas e sem uma conexão, significando Alagoas estes três territórios. Durante e depois da invasão batava, 1630-1706/1712, o quadro permanece inalterado, mas, sem dúvida, a experiência flamenga e a consolidação da colonização auxiliaram no fortalecimento das vilas e das freguesias. Em um terceiro momento, 1706/1712-1817, mais precisamente com a criação da comarca, uma identidade física começava a se moldar, percebendo-se o uso das expressões que denominavam a vila de forma isolada, tanto quanto a idéia de Vila e Capitania de Alagoas como um espaço único, porém, ainda submetido a Pernambuco. No último momento, 1817-1822, não só o termo Província das Alagoas remontaria a toda região, como representaria uma autonomia à Pernambuco e a costura identidária daquelas não tão mais dispersas regiões ${ }^{37}$.

\section{Fontes e Bibliografia:}

1. ALBUQUERQUE, Isabel Loureiro de. História de Alagoas. Maceió: Sergassa, 2000.

2. Arquivo Histórico Ultramarino, Alagoas Avulsos, Documentos 1, 8, 10, 21, 27, 76, 81, 93, 103, 113, 282 e 471

3. BHABHA, Homi. O Local da Cultura. Belo Horizonte: EDUFMG, 2007.

4. BICALHO, Maria Fernanda Baptista. "As Câmaras Ultramarinas e o Governo do Império" In: FRAGOSO, João; GOUVEIA, Maria de Fátima \& BICALHO, Maria Fernanda Baptista (Orgs.) O Antigo Regime nos Trópicos - A Dinâmica Imperial Portuguesa (Séculos XVI-XVIII). Rio de Janeiro: Civilização Brasileira, 2001, pp. 189-222.

5. BOXER, Charles R. O Império Marítimo Português. São Paulo: Companhia das Letras, 2002.

6. BRANDÃO, Moreno. História de Alagoas. Arapiraca: Edual, 2004.

${ }_{37}$ Queria fazer um agradecimento especial ao Arthur Curvelo, Dimas Marques, Alex Rolim, Mariana Marques, Jacqueline Castro, Claudio Cerqueira e Lanuza Pedrosa, bolsistas e colaboradores do Grupo de Estudos Alagoas Colonial (GEAC) que tem me auxiliado na transcrição desta "nova" documentação, bem como no debate destas "outras" idéias teóricas sobre a região em questão, sem os quais seria impossivel redigir e pensar estas páginas. 
7. CERTEAU, Michael de. A Invenção do Cotidiano. Petrópolis: Vozes, 2 Volumes, 1994.

8. DIAS, Maria Odila Silva. "A Interiorização da Metrópole" In: Carlos Guilherme Motta (Org.) 1822: Dimensões. São Paulo: Perspectiva, 1972, pp. 160-186.

9. FERRARE, Josemary. Marechal Deodoro: Um itinerário de Referências Culturais. Maceió: Catavento, 2002.

10. GINZBURG, Carlo. Mitos, Emblemas \& Sinais. São Paulo: Companhia das Letras, 1989.

11. GREENE, Jack P. Negotied Authorithies - Essays in Colonial Political and Constitucional History. Charlottesville/Londres: The University Press of Virginia, 1994.

12. HESPANHA, Antonio Manuel. As Vesperas do Leviatã - Instituições e Poder Político, Portugal Século XVIII. Coimba: Livaria Almedina, 1994.

13. HOLANDA, Sérgio Buarque de. Raízes do Brasil. São Paulo: Companhia das Letras, 2002.

14. http://pt.wikipedia.org/wiki/Capitania de Pernambuco, data 02/04/2010, $11: 55$.

15. JUNIOR, Caio Prado. Formação do Brasil Contemporâneo. São Paulo: Publifolha, 2000.

16. KOSELLECK, Reinhart. "Uma História de Conceitos: Problemas Teóricos e Práticos" In: Estudos Históricos. Rio de Janeiro, Volume 5, Número 10, 1992, p. 134-146.

17. LINDOSO, Dirceu. A Interpretação da Província: Estudo da Cultura Alagoana. Maceió: Edufal, 2005

18. LINDOSO, Dirceu. Formação da Alagoas Boreal. Maceió: Catavento, 2000.

19. MELLO, Evaldo Cabral. Rubro Veio - O Imaginário da Restauração Pernambucana. Rio de Janeiro: Toopbooks, 2002.

20. NOVAIS, Fernando. Portugal e Brasil na Crise do Antigo Sistema Colonial. São Paulo: Hucitec, 1995.

21. RUSSELL-WOOD, A. J. R. O Mundo em Movimento: os Portugueses na Ásia, África e América. Lisboa: Difel, 1998.

22. SALGADO, Graça (Coord.). Fiscais e Meirinhos - A Administração no Brasil Colonial. Rio de Janeiro: Nova Fronteira, 1985.

23. VERÇOSA, Élcio Gusmão. Existe uma Cultura Alagoana? Maceió: Catavento, 2002. 